\title{
Editorial
}

\section{Los antropólogos y nosotros mismos}

\author{
The anthropologists and ourselves
}

\author{
William Andrés Martínez-Dueñas ${ }^{1}$
}

\begin{abstract}
$\mathrm{P}_{\mathrm{r}}$ or coincidencia en los últimos volúmenes de Jangwa Pana (JP) a través de las editoriales he resaltado la reflexión sobre nosotros, científicos sociales, humanistas y especialmente antropólogos, como productores de representaciones de los otros. En tal sentido ese nosotros es Otro sobre el cual pensamos desde la distancia de los textos, los teclados y las pantallas. Esta reflexividad quizá resuelva en parte la pregunta sobre cuál es el estilo de la antropología en Colombia (o uno de tantos) y explique por qué esta comunidad de conocimiento toma su tiempo en dar respuesta a las preguntas que la sociedad le hace sobre política y cultura de manera urgente -esto no es un mea culpa -, quizá por el temor a presionar la herida colonial. Por otro lado, plantea las múltiples maneras (métodos y técnicas) que dan forma a las relaciones entre los actores académicos, sus otros y el Estado con sus proyectos de Nación.
\end{abstract}

En este sentido a través de las editoriales he manifestado preocupaciones e inquietudes sobre tres temas con cierta recurrencia en JP: 1) qué es o qué hace la(s) antropología(s) y los antropólogos (Vol. 17, No. 2); 2) cuál es el papel de las publicaciones académicas en ciencias sociales (Vol. 16, No. 2 y 3); y 3) cómo, por qué y para qué o quién escribir sobre el Caribe (Vol.17, No.3).

En un primer ejercicio revisamos cómo aparece el tema Caribe en JP en el periodo 2001 - 2016 para explorar el interés de los investigadores por publicar sobre este tema, que fue el énfasis del alcance (scope) del primer periodo de JP (periodo que denominaremos pre-indexación 2001-2009); dicho interés por promover el tema Caribe, según charlas de pasillo y un par de documentos, hacían parte de una estrategia para consolidar o promover una "Identidad Caribe" desde la Facultad de Humanidades de la Universidad del Magdalena, en tal sentido se podría deducir que el papel del antropólogo, en este lugar, y de sus medios de divulgación científica era consolidar, sistematizar, validar y promover dicha identidad con referente geopolítico. En otras editoriales y gracias a los aportes de nuestros autores y editores invitados propuse preguntas sobre el Caribe, con el ánimo de invocar y provocar otras voces que quieran, puedan o deseen hablar sobre este tema en nuestra revista. Sabemos que ahí están y queremos leerlos.

\footnotetext{
${ }^{1}$ Editor en jefe revista Jangwa Pana - Dr. Antropología. Profesor asociado programa de Antropología, Facultad de Humanidades, Universidad del Magdalena. Colombia. Correo electrónico: wmartinez@unimagdalena.edu.co. ORCID ID: 0000-0003-0921-1149
} 
$\mathrm{Si}$ bien en volúmenes anteriores se han presentado reflexiones y análisis sobre el quehacer de los antropólogos (culturales, arqueólogos, biológicos), en los dos últimos volúmenes el tema sobre la antropología y los antropólogos ha tenido contribuciones remarcables; en primer lugar, la traducción al español de la entrevista a Eduardo Viveiros de Castro sobre ¿quién es indígena en Brasil? (Viveiros de Castro, 2018) y en este número editado por Daniel Velandia y Claudia Cáceres sobre el papel de los antropólogos en las instituciones del Estado. En ambos casos se trata de cómo el ser antropólogo y hacer antropología se produce en medio de unas intra $^{2} \mathrm{e}$ inter-acciones entre la proyección socio-jurídica de nación que emana desde el Estado, las apropiaciones de esta por parte de los diversos sujetos que componen dicha nación y los expertos en unir los diversos puntos entre los dos anteriores. Si bien la perspectiva de Viveiros se ubica del lado del antropólogo con los múltiples otros, se podría decir que en este número especial (Dossier) es desde la perspectiva del antropólogo entre el Estado/instituciones y las comunidades con las cuales trabaja. Esta mirada, aunque simplifica la relación Otro[s]-Estado-Antropólogo[Nación] (por fortuna ampliada en este número) deja ver cómo el territorio, espacio o lugar desde el cual se proyecta la relación con el Otro, determina la práctica y la reflexión sobre/con el Otro. Entonces mientras que con Viveiros se planteaban respuestas a la pregunta del Estado[Nación] sobre “qquién es indio?” en medio de las reconfiguraciones sociales, políticas y ontológicas de la(s) nación(es), en este caso Brasilera; en este número la reflexión está encaminada a ampliar la pregunta sobre qué es ser antropólogx en Latinoamérica a través de excavar y pensar las experiencias de antropólogos y antropólogas que han trabajado en la intersección entre el Estado y comunidades en Argentina, Colombia y México, con especial interés en las generaciones de finales del milenio que vieron su práctica profesional transformada por los

\footnotetext{
${ }^{2}$ Uso intra-acción para hace evidente las relaciones entre diversos actores, leyes, procesos que se coproducen como sujetos que se sujetan a ellos mismos,
}

cambios jurídicos originados por la implementación de políticas transnacionales relativas al multiculturalismo (ver Velandia y Cáceres en este número) y como plantea Claudia Cáceres (en este volumen) indica la necesidad de hacer más antropología de las instituciones y el Estado y más antropología de los titulados en antropología en dichas instituciones, donde una herramienta como la investigación compartida de la que nos habla Daniel Velandia puede ser adecuada para visibilizar y entender esas cajas negras del trabajo antropológico y a partir de ello generar acciones concretas sobre la disciplina y sus sujetos.

En este sentido y retomando el lugar desde el cual escribo estas líneas vale la pena mencionar que nuestro programa de formación de antropólogos en la Universidad del Magdalena, si bien tiene un núcleo de fundamentación curricular boasiana en los primeros semestres, cuenta con diferentes componentes que fortalecen las competencias críticas, autocríticas y analíticas de nuestros futuros colegas con asignaturas referentes a problemáticas locales y regionales que van acompañadas de seminarios como antropología en Colombia y antropología del desarrollo que exploran la relación que como "especialistas en la alteridad" tenemos con el Otro, que en muchos casos, sino todos, somos nosotros mismos.

En este número, además del Dossier "Antropología en el contexto gubernamental: incidencia pública de la disciplina desde el poder ejecutivo", presentamos la continuación del Dossier "Migraciones y fuerza laboral en el Gran Caribe, siglos XIX y XX" (Vol. 17, No. 3, ver editorial de Jorge Elías Caro). En la sección general contamos con dos contribuciones: una sobre la complejidad desde la reflexión matemática, invitándonos a pensar sobre las difusas fronteras entre las ciencias exactas y las ciencias sociales; la otra es un artículo de investigación biopsicosocial

en este caso, con un énfasis en tecnologías jurídicas y antropológicas (cf. Barad, 1999). 
sobre los efectos del conflicto armado en la salud mental de una comunidad rural en el suroccidente colombiano y cuáles serían las salidas para afrontar dichos efectos desde una perspectiva que integre las experiencias locales y las académicas.

Invitamos a nuestros lectores a consultar la oportuna carta al editor de Camilo Aguilera, Isabela Figueroa y Felipe Moreno, que espero haya llegado al destinatario adecuado, sobre la manifestación política pacífica relativa a la desfinanciación universitaria en Colombia que se dio en la Universidad del Magdalena; que esta sea una oportunidad para reconocer el esfuerzo de nuestros estudiantes por fortalecer la educación superior pública y de calidad ¡Viva la U!

\section{Referencias}

Barad, K. (1999). Agential realism. Feminist interventions in understanding scientific practices. En M. Biagioli (Ed.). The science studies reader (pp. 1-11). New York, USA: Routledge.

Viveiros de Castro, E. (2018). En Brasil, todos son indios, excepto quien no lo es. Jangwa Pana, 17(2). 